\title{
第
}

\section{PARQUE DOS SENTIDOS}

\author{
SALES, Fernanda Rocha \\ Universidade Federal do Ceará, Graduada em Arquitetura e Urbanismo. \\ e-mail: fernandarsales@gmail.com.br
}

\begin{abstract}
RESUMO
O estilo de vida moderno tem tornado muitas pessoas estressadas e isoladas em seus universos particulares. As responsabilidades cotidianas exigem comprometimento heroico, ao passo que os momentos de ócio vão se tornando mais e mais raros. O presente trabalho propõe um lugar agregador, estrategicamente conceituado, permitindo que todos se sintam estimulados a experimentar e/ou intensificar as sensações adormecidas. Assim, o projeto tem como base fundamental os princípios da acessibilidade, visto que uma considerável parcela da população especialmente pessoas com deficiência ou dificuldade de locomoção - além de estar inserida nesse cotidiano caótico e desgastante, possui uma série de direitos negados.
\end{abstract}

Palavras chave: sensações; acessibilidade; pessoa com deficiência, direitos.

\begin{abstract}
The modern lifestyle has made many people stressed out and isolated in their particular universes. Day-to-day responsibilities require heroic commitment, while moments of leisure are becoming more and more rare. The present work proposes an aggregate place, strategically conceptualized, allowing everyone to feel stimulated to experiment and / or intensify the dormant sensations. Thus, the project has as its fundamental basis the principles of accessibility, since a considerable part of the population - especially people with disabilities or difficulty of locomotion - besides being inserted in this chaotic and exhausting daily life, has a series of rights denied.
\end{abstract}

Keywords: leisure; sensations; accessibilty; disabled people, rights.

\section{INTRODUÇÃO}

Tendo em vista que certos aspectos da vida moderna em uma cidade das dimensões de Fortaleza afastam e até privam seus habitantes do convívio em sociedade e com a natureza, o vigente trabalho objetivou entender como e porque essa problemática acontece para que fosse possível apresentar uma solução eficaz. Assim, o Parque dos Sentidos surgiu como uma forma de unir pessoas com as mais diferentes complexidades para usufruírem em igualdade de um lugar cheio de estímulos e atividades variadas.

A proposta é estabelecer esse vínculo através dos sentidos humanos, despertar as sensações que se encontram adormecidas por motivos diversos, através de experiências múltiplas dentro de uma atmosfera de comunhão e afeto. Uma pessoa cega pode apreender o espaço através de texturas, sons, temperaturas, um usuário de cadeira de rodas pode se locomover confortavelmente em um jardim repleto de cores e sabores, assim como quem não possui deficiência física ou sensorial pode vivenciar o mundo com foco em outro 


\section{(x) $^{\text {remax }}$}

aspecto que não o visual. Essa questão foi mais bem discutida por Juhani Pallasmaa em "Os Olhos da Pele":

Se não usar todos os seus cinco sentidos, alguns deles irão atrofiar, enquanto os outros sendo enfatizados e muito utilizados irão evoluir em novas formas. No atual estado da civilização humana, a maioria da nossa energia percebida é absorvida pelo impacto visual. Os sinais visuais e acústicos parecem depender menos nas estruturas dos edifícios do que o cheiro, o gosto ou o toque. Em outras palavras, a nossa cultura pende mais para valores imateriais do que nos períodos anteriores. (Pallasmaa, 2006)

Assim, no Parque dos Sentidos, concebido como um espaço de integração, onde determinada deficiência pode significar o despertar de um sentido, é possível que pessoas com problemas distintos reúnam-se na busca por uma solução em comum. A proposta é ampla e nova, no sentido de que não se destina apenas a uma parcela da população, já que os sentidos humanos encontram-se atrofiados para muitos. Nesse lugar, com atividades diversas e universais, porém com foco nas pessoas com deficiência, será possível encontrar mecanismos suficientes para a superação de dificuldades.

\section{SER PESSOA COM DEFICIÊNCIA NA TEORIA E NA PRÁTICA}

Apesar de os obstáculos para a vida em comunidade serem vários, como os de cunho psicológico, físico ou mesmo pela falta de segurança, as grandes cidades brasileiras, como Fortaleza, dificilmente possuem locais públicos adequados para pessoas com deficiência e dificuldade de locomoção. Muitas vezes essas pessoas preferem permanecer em suas casas a terem que passar por problemas advindos do descaso do Poder Público, que não oferece espaços devidamente projetados nem tampouco lugares inclusivos de interesse coletivo. A deficiência, sentida como uma restrição social, pode ser sentida em consequência de ambientes sem acessibilidade, questionamentos sobre a inteligência e competência, inabilidade no uso de linguagem de sinais em espaços públicos, entre outras situações (OLIVER, 1990, p. xiv).

Segundo o Censo de 2010 realizado pelo Instituto Brasileiro de Geografia e Estatística (IBGE), há no Brasil cerca de 45 milhões de pessoas com algum tipo de deficiência, o que equivale a quase $25 \%$ da população brasileira. Dentre as regiões do país, a nordeste é a que mais possui pessoas com deficiência ( $26,6 \%$ da população). No que diz respeito ao grau de severidade, a região também está no topo do ranking, sendo que a deficiência visual, com $4,1 \%$ da população, é a que mais possui pessoas nessa séria condição (Cartilha IBGE, 2012, P.6).

É fato que as pessoas com deficiências mais aparentes carregam consigo mais estigmas, porém há outras deficiências, silenciosas, como transtornos mentais como depressão e ansiedade. A existência humana é também processo de mudanças quando nos lembramos, por exemplo, do bebê, da gestante, do obeso, do idoso. A essas pessoas com foi convencionado o termo pessoa com mobilidade reduzida:

Uma pessoa com mobilidade reduzida é aquela que, temporária ou permanente, tem limitada a sua capacidade de se relacionar com o meio e de utilizá-lo. Entende-se por pessoa com mobilidade reduzida aquela com deficiência, a idosa, a obesa e a gestante, entre outros (NBR 9050:2004).

Se esses indivíduos possuem uma deficiência, é certamente em relação a alguma coisa. João Frayse-Pereira (1985, p.20) se referiu à loucura, mas poderia facilmente ter se referido às deficiências em geral, quando diz que é normal "o indivíduo cuja maneira de ser é relativa 
a uma outra maneira de ser. E esta não é uma maneira de ser qualquer, mas a maneira normal de ser.". Assim, é imposta uma exigência a nossa existência, tão diversificada.

A maneira como historicamente nossa cultura se formou acabou delegando a essas pessoas a imagem de deformação do corpo e da mente: elas denunciam a imperfeição humana. Porem, as deficiências fazem parte da nossa condição, e conviver com elas deve fazer parte do nosso cotidiano. Como diria Foucalt (2000, p.85), "a doença só tem realidade e valor de doença no interior de uma cultura que a reconhece como tal." O que é possível considerar sobre a pluralidade cultural e humana é que, em todas as sociedades, o desvio da norma é a essência das dificuldades e preconceitos.

Possuir deficiência não é sinônimo de viver em sofrimento ou tragédia. Ser contra essa ideia não significa ignorar as necessidades e lutas da pessoa com deficiência, mas abrir a discussão sobre como a sociedade deveria se portar sobre a diversidade de estilos de vida. $\mathrm{Na}$ fala de Debora Dinis, autora de "O que é deficiência?", além de a deficiência ainda não ter se libertado da autoridade biomédica, ela ainda é considerada uma tragédia pessoal, e não uma questão de justiça social. (2007, p.11)

Sendo assim, o que limita a participação dessas pessoas na sociedade seria o corpo ou os contextos pouco sensíveis à diversidade? Essa pergunta deve ser constantemente avaliada para, a partir daí, mudarmos a forma como convivemos com as nossas deficiências. Apresentar soluções de inclusão deve ser mais que um instrumento de justiça social, mas algo natural em uma sociedade que conviva respeitosamente com as mais diversas condições de vida.

\section{PARQUE DOS SENTIDOS - O PROJETO}

Foi procurado um sítio amplo o suficiente para a abrangência do programa de necessidades, que inclui eventos de interesse público com demandas numerosas, como festivais, congressos e encontros. Além disso, que possuísse uma boa localização em Fortaleza, no caso no Bairro Manuel Dias Branco, que possui a presença do Rio Cocó e é próximo à praia. Sua geomorfologia é composta por áreas de dunas fixas, em sua maioria, de mangue e lençol freático (Santos, 2006).

Segundo dados do IBGE (2010), o bairro apresenta uma baixa densidade, o que facilitaria a relocação das edificações residenciais dentro da área do Parque para terrenos vizinhos, já que seu entorno possui espaços livres. O ponto negativo é que essa região do bairro possui carência em vários aspectos, como infraestrutura e mobilidade. É sugerida, então, a alteração de certas vias de modo a facilitar o ingresso de visitantes por ônibus através da Praça de Entrada, além de uma estação de tratamento de água (ETA) e outra de esgoto (ETE) para resolver o problema das fossas clandestinas que desaguam no Rio Cocó.

Completamente inserida dentro da Macrozona de Proteção Ambiental, segundo o Plano Diretor Participativo de Fortaleza, importante ressaltar uma zona próxima ao Rio Cocó, a ZPA 1, que prevê a preservação do meio ambiente e de seus recursos naturais, o incentivo e a promoção de pesquisa científica, o desenvolvimento de atividades de educação ambiental e o turismo ecológico (2008). Essa zona será acessada por pequenos grupos de visitantes auxiliados por guias, através de uma ponte elevada acessível, onde terão contato com a fauna e flora de Fortaleza, além de uma experiência sensorial estimulante. A Lagoa do Amor, de rico potencial paisagístico, também possuirá sua margem preservada e, portanto, de acordo com a legislação.

O Parque dos Sentidos é idealizado como lugar com arquitetura acessível não apenas nas normas técnicas, mas também no programa de necessidades, com foco nos sentidos humanos que, hoje, são negligenciados. Seus caminhos e áreas internas foram concebidos 


\section{(x) $^{\text {remax }}$}

com caráter de saúde, lazer, terapia, encontro e passeio despreocupado. Precisamos ter atenção por onde caminhamos, vemos detalhes antes ignorados. Estamos ao dispor do clima e da natureza, com a possibilidade de estabelecer contato próximo com outros seres vivos e de sermos obrigados a sentir odores e escutar o som por onde passamos. Foram desenhados vários caminhos que levam ao mesmo lugar, pois foi entendido que assim se criaria uma gama maior de sensações, onde caminhos diferentes podem ser identificados por aromas, cores e sons.

Para que esse caminhar ocorra de modo leve e acessível, foi idealizada uma pavimentação inclusiva que informa os diversos visitantes, por meio de suas características específicas, como e onde encontrar as atividades desejadas. Elas começam na praça de entrada e estarão presentes em toda a extensão do Parque. Possui três revestimentos básicos: a pedra granítica Quixadá na cor cinza, sem polimento, em lajes de 1,00m x 1,60m e sem junta de dilatação entre as pedras, com piso direcional, escolhido para pessoas com deficiência física ou mobilidade reduzida por não possui nuances que possam comprometer a mobilidade despreocupada desses indivíduos; outro revestimento, similar ao anterior, porém com junta de $10 \mathrm{~cm}$ com grama, para pessoas que desejem percorrer trechos sentindo o contato da vegetação nos pés; o revestimento da ciclovia, que é o paralelepípedo com acabamento em granito e sem juntas, pintado na cor azul e com fluxo nos dois sentidos, mas que no interior do Parque se transformará em uma ciclofaixa, pintada na cor azul, com pavimentação em pedra Quixadá com junta e sem junta, dependendo do caminho.

Nas encruzilhadas entre os caminhos serão implantados pisos com tótens informativos em alto relevo e em braile, informando corretamente a direção de atividades próximas. Além disso, o piso direcional possuirá angulações suaves, seguindo os caminhos também angulosos do Parque de forma a sair da monotonia da linha reta sem, contudo, que o usuário caminhe mais que o necessário.

Existirá outro elemento em certos caminhos internos do Parque: córregos com água corrente. Eles despertarão o sentido da audição e do tato, deixando as pessoas mais próximas da natureza e tornando essas vias únicas.

As árvores estarão em todas as áreas e caminhos do Parque, pois, em uma cidade com o clima de Fortaleza, quente praticamente o ano inteiro, espera-se que as sombras tragam ainda mais comodidade ao passeio e ainda mais sensações aos visitantes através de seus perfumes, cores e texturas peculiares. Elas também servirão como cercas vivas no perímetro do Parque, de forma que o lugar esteja protegido, mas não possua a aparência de estar enclausurado.

As outras atividades do Parque, como o Espaço Ecumênico, a Lagoa dos Bichos, o Labirinto de Ervas, os Campos Floridos com Borboletário, o Aviário, o Playground, os Campos de Piquenique, os Jatos de Água, as pequenas praças com quiosques, banheiros acessíveis e fontes, foram implantados de modo aos caminhos ficarem dinâmicos e munidos com mobiliário, placas, totens informativos acerca de suas diversas atividades (Ver Anexo).

\subsection{Praça de Entrada}

Com acesso pela Avenida Aldy Mentor, no contorno frontal do projeto, foi ali situada a facilitar a chegada de veículos e pedestres vindos de todas as regiões da cidade. Nela, já é possível sentir o espírito do Parque, pois os caminhos estão protegidos pela sombra das árvores, e o respeito coletivo pode ser vivenciado pelos diferentes elementos de acessibilidade, como sinalização tátil, faixa de pedestres elevada, semáforos sonoros e pisos destinados a cada especificidade que as pessoas possam vir a ter. 


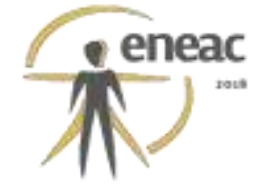

$\mathrm{Na}$ praça haverá um marco visual onde já serão encontradas informações sobre as atividades do Parque dos Sentidos, com portaria próxima para controle de veículos utilizados na manutenção interna, como ambulância e pick-ups com seguranças, e que também inspecionará a entrada e saída de visitantes (Ver Figura 9).

Os dois estacionamentos, um para veículos particulares e outro para veículos coletivos, foram locados distantes da avenida, de modo a garantir área suficiente para a praça, onde haverá um marco com informações iniciais. As duas áreas totalizam 289 vagas para veículos maiores e menores e dessas, 64 para pessoas com deficiência.

Duas grandes áreas, próximas a cada estacionamento, serão preservadas com a conservação de seu solo natural, com cultivo de novas espécies de vegetações. Em uma delas, próximo ao Estacionamento de veículos coletivos, serão implantados um skate parking e um playground com quiosques e banheiros acessíveis, sombreados pela copa das árvores durante o dia e bem iluminados durante a noite, onde moradores do entorno possam se divertir de forma confortável e independente do funcionamento do Parque (Figura 1).

Figura 1: Estacionamento para veículos coletivos, skateparking e playground, quiosques e área com vegetação conservada e divisa com recepção na Praça de Entrada.

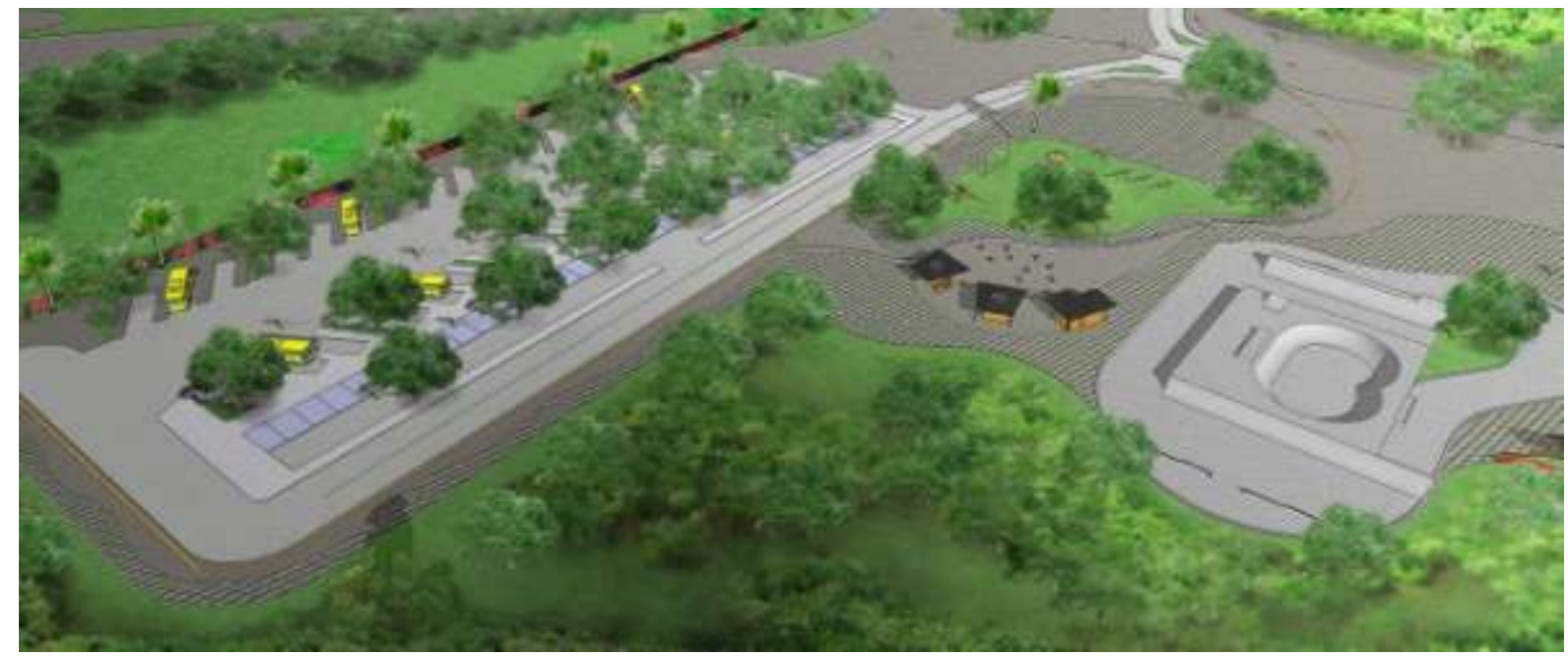

Fonte: Imagem produzida pela autora.

\subsection{Recepção}

Definida a zona de entrada do Parque, a Recepção com Administração foi situada de modo a ser possível enxergar todo o seu potencial paisagístico, com lugares para sentar. Nessa zona se inicia a ciclofaixa, que percorrerá seus caminhos internos e também é possível encontrar informações gerais sobre as várias atividades e programações (Figura 2).

Informações mais precisas e um lugar devidamente destinado à reunião de grupos de visitantes serão encontrados na Administração, área diretamente ligada à Recepção. Dali o visitante encontrará apoio para conhecer com mais comodidade esse lugar, com possibilidade de solicitação de mecanismo mais eficiente para os passeios, como cadeira de rodas eletrônicas, scooters, e pequenos veículos movidos à energia renovável. Nessa área poderão ser encontrados também serviços ambulatoriais para procedimentos simples, caso ocorra necessidade. A Administração é o centro dos serviços de manutenção, é nela que são encontradas as pessoas que cuidam do Parque e que o gerem, como a gerência da 


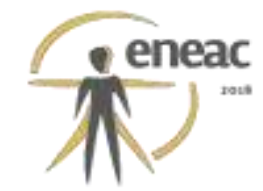

estocagem de alimentos e reciclados, a arrecadação de doações, a organização de eventos culturais, a ouvidoria, a diretoria, entre outros.

Figura 2: Recepção e Administração com visão para a Lagoa do Amor.

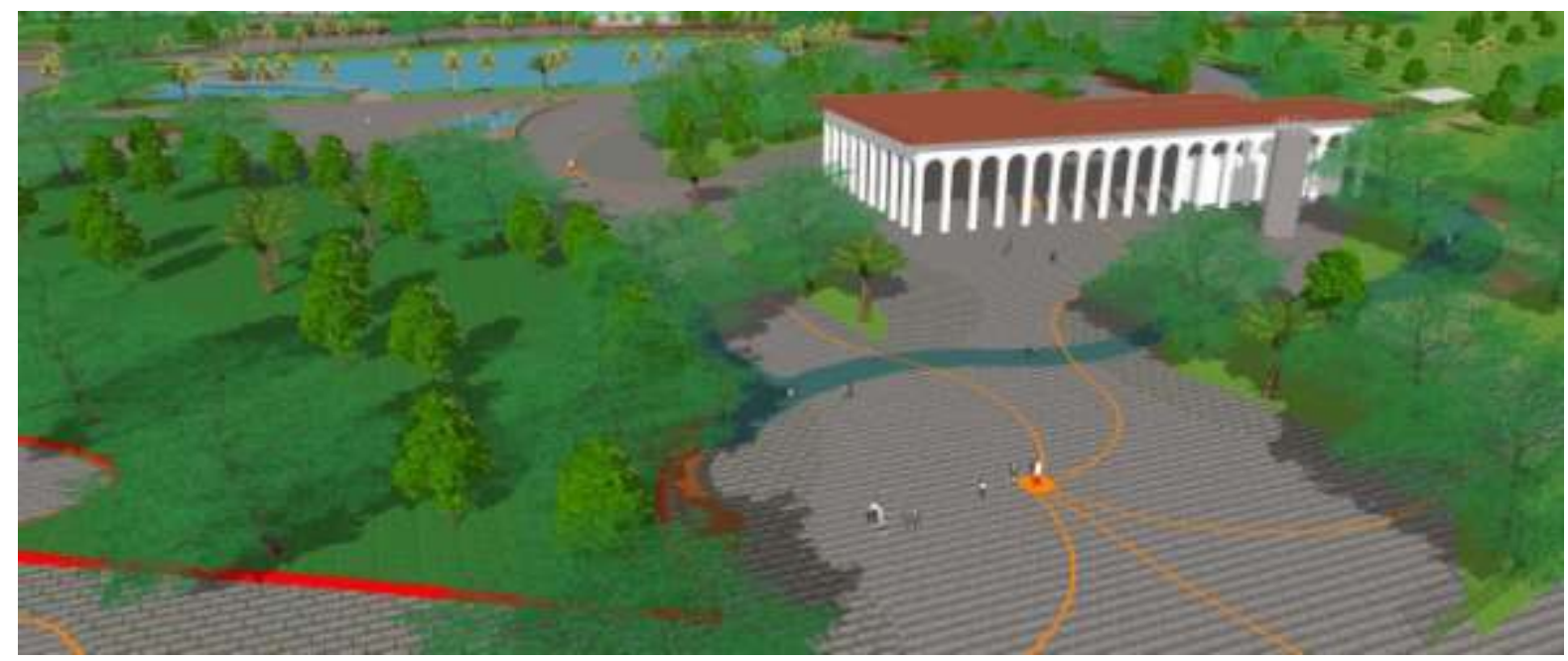

Fonte: Imagem produzida pela autora.

\subsection{Lagoa do Amor}

Quando foi decidido que, tanto quanto suas edificações e atividades internas, os fluxos possuiriam importância similar, o contorno do Parque ganhou seus primeiros rabiscos. A Lagoa e seu redor, de grande potencial paisagístico e sensorial foi, desde o início, concebida como local focal para se caminhar, conversar, observar as diferentes paisagens emolduradas pelas árvores. A Lagoa do Amor é como o coração do Parque, de onde suas veias, ou fluxos, se acessa facilmente qualquer ponto (Figura 3).

Figura 3: Lagoa do Amor com ponte, Anfiteatro, tanque de peixes e Administração ao fundo.

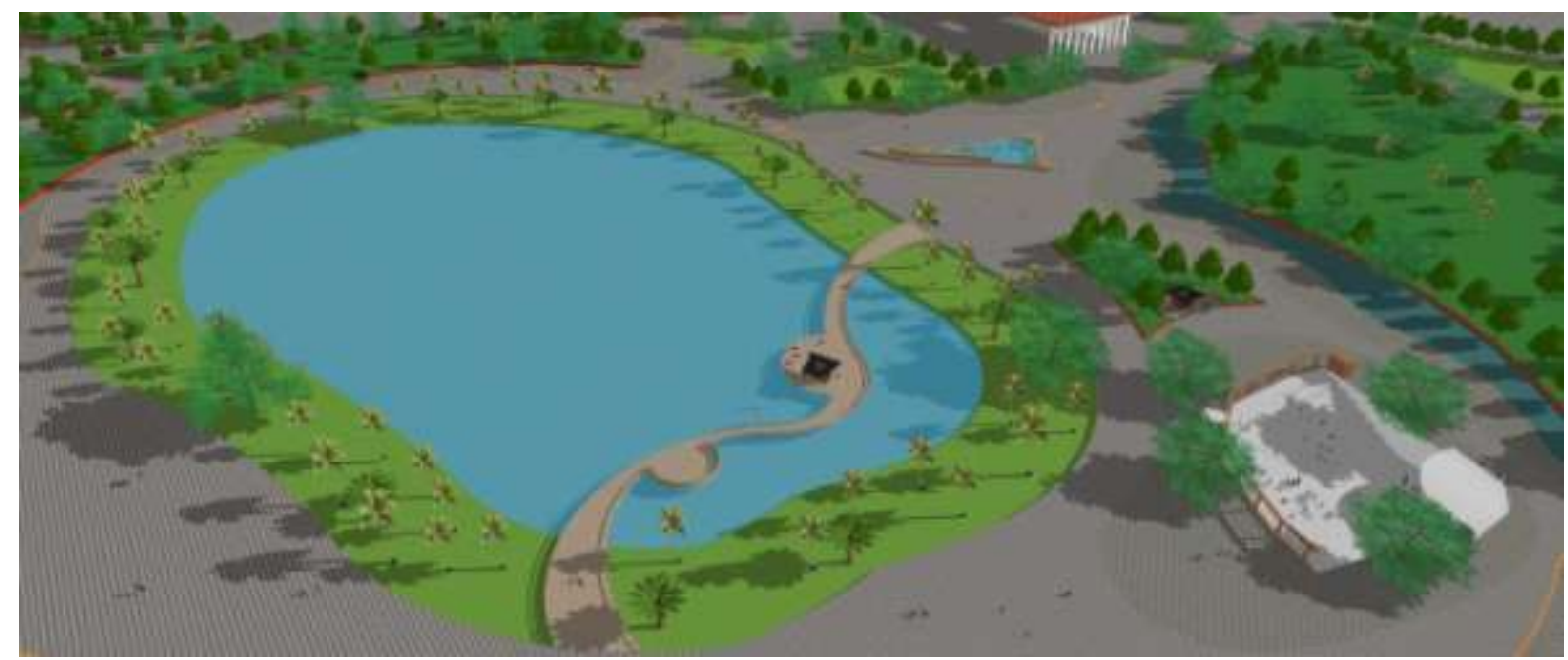

Fonte: Imagem produzida pela autora. 


\section{(x) $^{\text {remax }}$}

No entorno do espelho d'água de tudo pode ser encontrado, como quiosques com produtos diversos, pequenas praças, Anfiteatro amplo, uma grande área com jatos de água saindo do chão e uma longa ponte onde as pessoas podem apreciar a lagoa. No caminho da recepção para a Lagoa o visitante já encontra uma prévia desse amplo recurso natural: um tanque estilizado com peixes ornamentais.

As praças da Lagoa do Amor, lugares de encontro e conversas, possuem comodidade para ampliar o relacionamento entre as pessoas. Com formas circulares, elas são como nichos recortados dos jardins. A maioria desses jardins é elevada, o que é interessante para pessoas em cadeiras de rodas, pois assim elas podem tocar a vegetação com mais comodidade. Essas praças estarão equipadas com mobiliário em diversos pontos, alguns com fontes e outros com quiosques, todos bem protegidos pela sombra das árvores.

O Anfiteatro é acessível e destinado às apresentações artísticas, palestras e encontros. Pessoas com deficiência ou mobilidade reduzida podem dirigir-se aos bancos através de rampas seguras ou de elevador instalado em uma das extremidades da entrada. Essa edificação também estará protegida pelas copas de árvores frondosas e guarnecida por quiosques próximos.

\subsection{Fazendinha}

A Fazendinha foi locada próxima ao Pesque e Pague, área existente com restaurante onde pode se pescar o próprio peixe, já que as áreas possuem atividades similares. É proposto um acesso que facilite a ligação entre esses locais. A interface dessa zona é bem similar a de uma fazenda do interior, com seus cheiros e sons peculiares. Contem ainda carnaubeiras e coqueiros no entorno, construções avarandadas e com telhado característico, amplo pasto com animais típicos. Na Casa Grande haverá duas salas multiuso, onde poderão ocorrer encontros, aulas, pequenas exposições, entre outras atividades.

No pasto, ampla área cercada, possuirão animais como cavalos, jumentos, vacas, ovelhas, galinhas e porcos. As pessoas que desejem vê-los mais de perto procurarão os guias e assim será possível tocar nos animais mais mansinhos, beber o leite das vacas e ovelhas, cavalgar nos cavalos, entre outras experiências que, hoje, encontram-se tão esquecidas em nossa cidade urbanizada (Figura 4).

Figura 4: Fazendinha acima e área de piquenique abaixo à esquerda e Campos Floridos com borboletário no centro à direita.

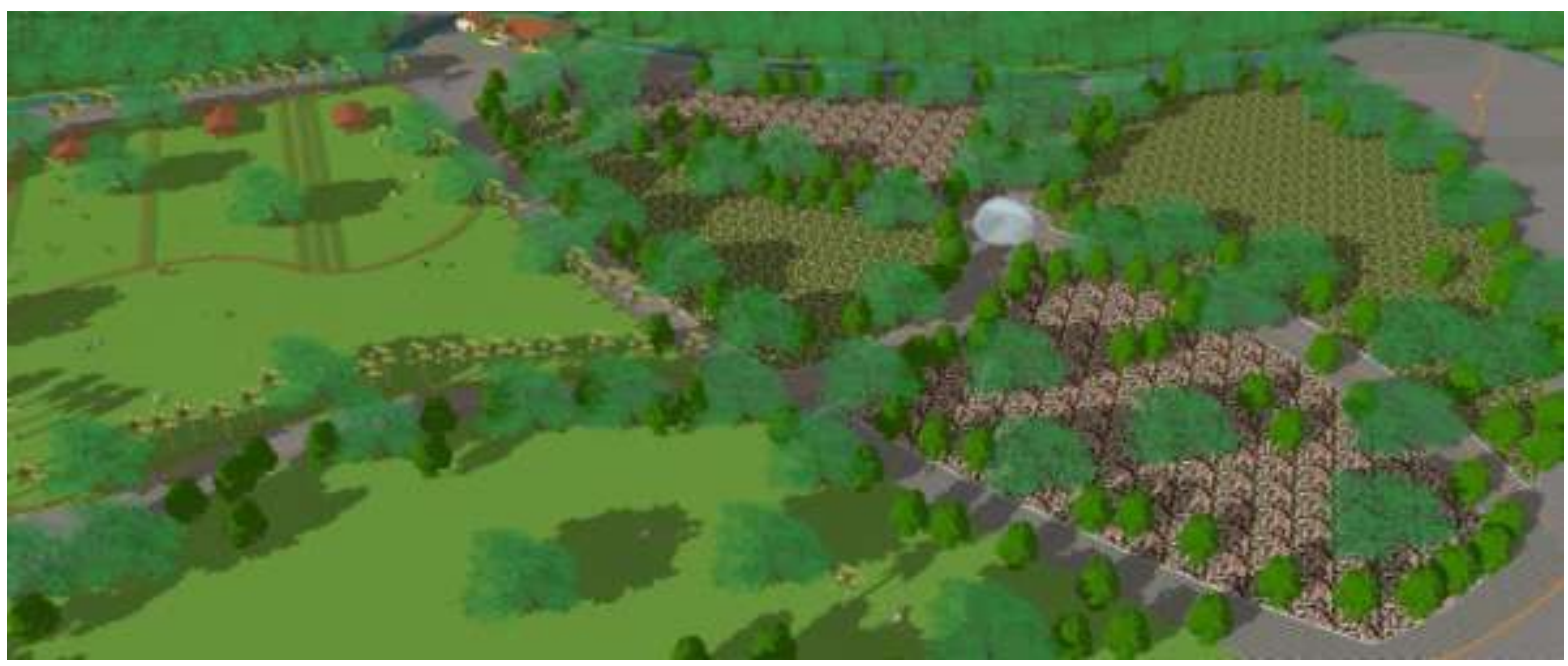

Fonte: Imagem produzida pela autora 


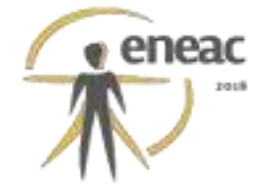

Em seu terreno é encontrado ainda os Campos Floridos, quatro grandes áreas com plantas floríferas, principalmente as nativas de nossa região. Elas serão de médio porte, como ipês amarelo, roxo e verde, cássia rosa, entre outras, e de pequeno porte, como catingueira, crisântemo, helicônia, maracujá do mato, violeta da caatinga, entre outras. No cruzamento entre essas áreas, no centro, encontra-se um borboletário (Figura 4).

No caminho para a Zona de Esportes, é encontrada uma pequena Lagoa dos Bichos, com animais aquáticos como peixes e patos. De lá, uma vista estonteante do Parque, pois é proposta uma ponte que faz a ligação entre a área da Horta e a de Piqueniques. Na área de piquenique e, mais reservado, o Espaço Ecumênico, lugar de silêncio, meditação e reflexão.

\subsection{Esportes}

Esse espaço possui importância tremenda para o Parque dos Sentidos e para as pessoas com deficiência, pois representa a possibilidade de superação através do corpo, mostrando as capacidades e evoluções que cada um pode alcançar. Está ligado ao Clube dos Diários, edificação vizinha existente que foi mantida no projeto pelos usos similares que as duas áreas possuem. Além de quadras de esportes, o Clube possui piscina com raia, que pode ser utilizada pelos usuários que desejem práticas um pouco mais profissionais. Dentro do Parque, os exercícios realizados terão um caráter mais leve, de socialização e encontro, bem como de práticas de fisioterapia. São as duas áreas principais, uma com os Campos Gramados, para quem deseje desempenhar exercícios diversos ao ar livre, e a edificação em si, que conta com uma quadra poliesportiva coberta, com hidromassagem com vestiários e outras duas salas multiuso. Relevante destacar que serão implantados mais quiosques com a venda de produtos como sucos naturais, saladas e sanduíches, pois a prática de esportes exige fisicamente dos usuários (Figura 5).

Figura 5: Zona de Esportes.

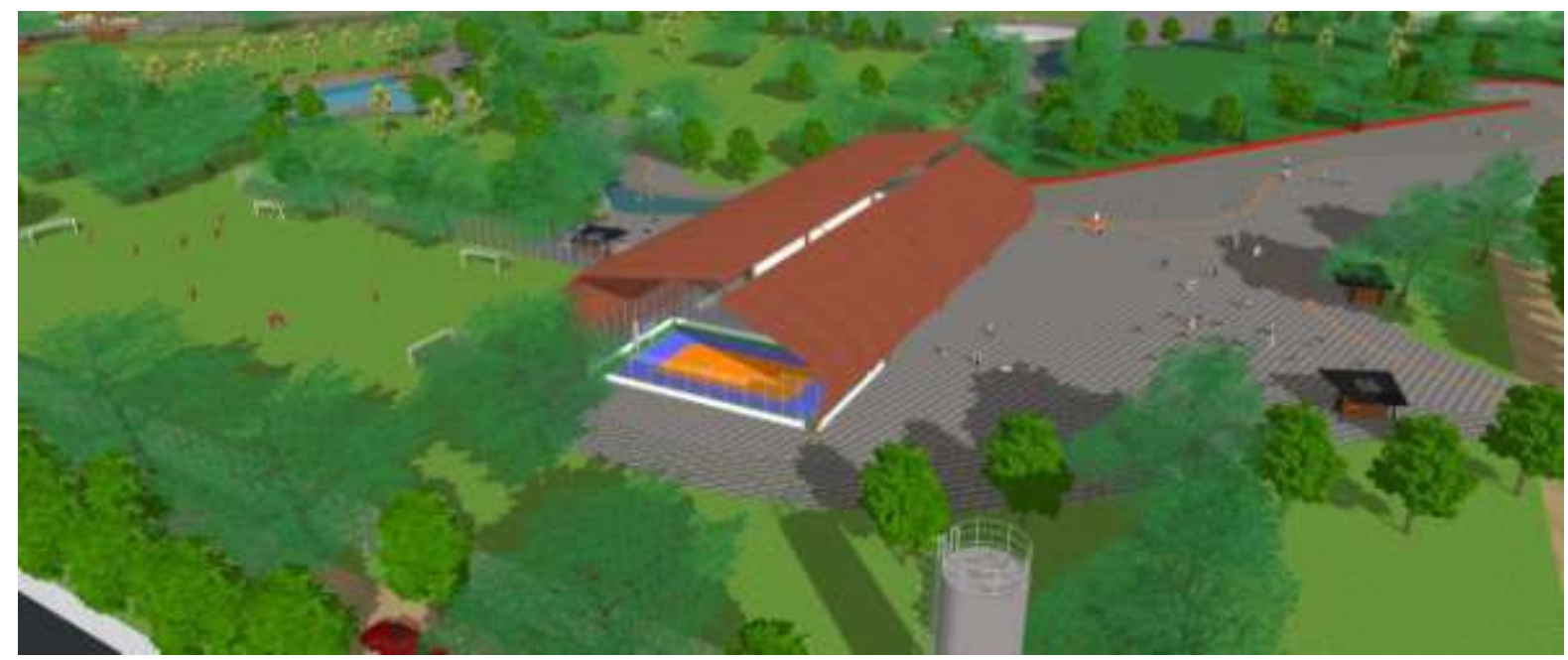

Fonte: Imagem produzida pela autora.

\subsection{Fórum dos Sentidos}

De importância crucial, é onde serão debatidos, pesquisados e realizados avanços referentes às pessoas com deficiência, e onde todos podem se unir na busca da garantia de seus direitos. Está situado próximo à Área de Proteção Ambiental, possuindo, dessa forma, uma visão estonteante da vegetação ali instalada e do bosque com árvores frutíferas 


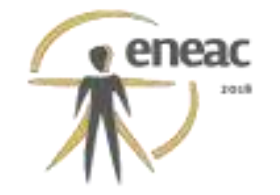

localizadas antes da entrada para essa área. Nessa edificação, todos os sentidos humanos serão despertados, mas haverá um foco especial nos sentidos do paladar e olfato, pois ali existirá um restaurante e salas multiuso que poderão ser ministradas aulas de culinária, onde toda a matéria prima gerada no Parque, como as frutas, os legumes, as folhas, as ervas, o mel, o leite, os ovos, serão apreciadas como ideal de alimentação gostosa e saudável. A edificação conta ainda com um auditório, uma biblioteca, um café, salas multiuso e áreas administrativas (Figura 6).

Figura 6: Fórum dos Sentidos, início do Labirinto das Ervas à esquerda.

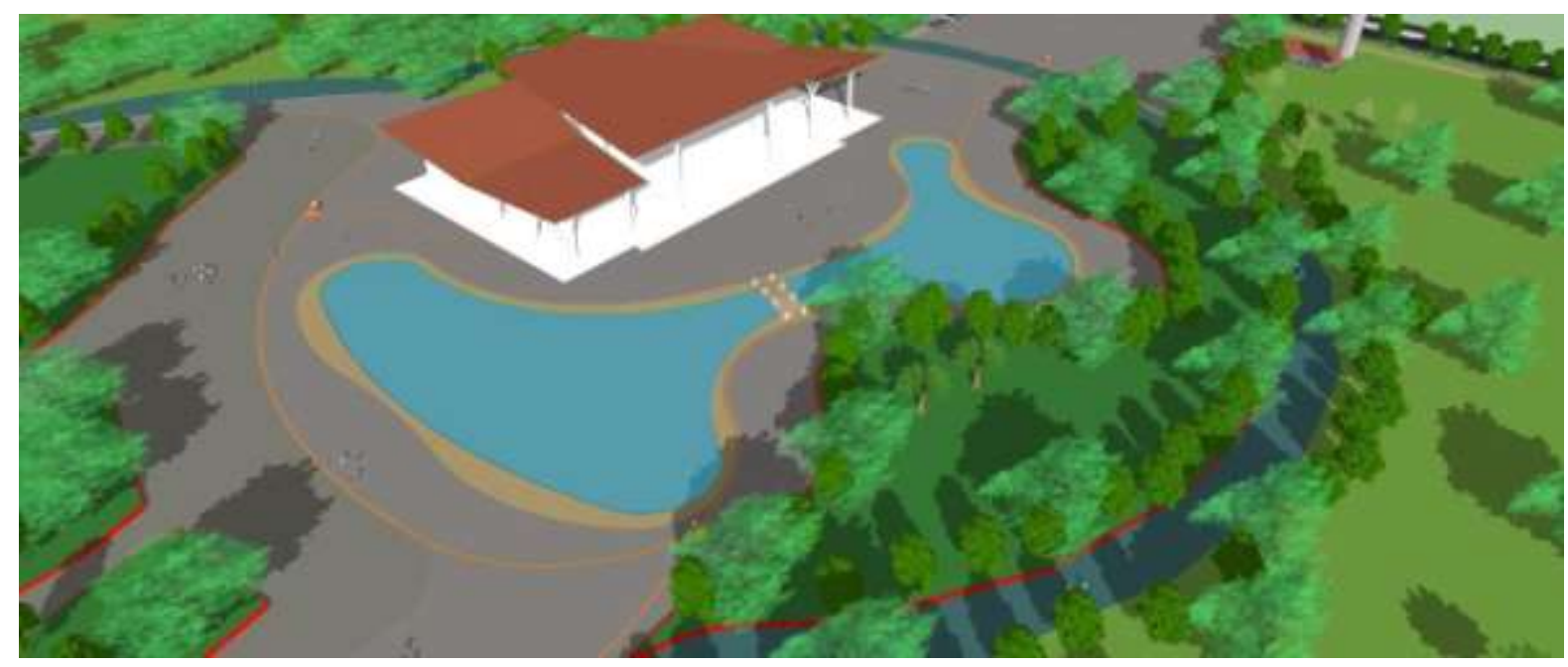

Fonte: Imagem produzida pela autora.

Seu terreno conta ainda com o Labirinto de Ervas, com foco no olfato, e poderão ser comercializadas nos Quiosques como forma medicinal e também no preparo de pratos para o restaurante. As ervas encontram-se em áreas de jardins elevados, para que todos os visitantes possam tocar nas plantas com fafacilidade. O Labirinto não é complexo, é de fácil assimilação para os usuários, mas mesmo assim, existirão guias para garantir que todos circulem sem grandes problemas.

\subsection{Zona de Proteção}

Nessa zona há uma única edificação, de onde os visitantes poderão desbravar a fauna e flora do mangue com o auxílio de guias. A edificação, bastante aberta, contém duas salas multiuso. Para acessar a sala no primeiro andar, o visitante utilizará um elevador monta carga, necessário, pois a trilha será toda em palafitas, o que causaria o mínimo de problemas para o solo e para a fauna e flora locais. A trilha possui uma largura de 3 metros, e, no máximo de 150 em 150 metros, áreas cobertas para descanso com mapas de localização. Essas áreas podem ser de dois tipos: as que se encontram no cruzamento entre os caminhos, por onde os visitantes precisam entrar para continuar o percurso, e áreas de descanso que estão apenas ao lado da trilha, onde o visitante não precisa entrar 


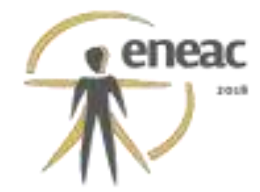

se assim desejar. A trilha tem início da referida edificação e vai direto até uma das áreas cobertas, de onde se divide em três. Todas levam ao píer existente no Rio Cocó, área com uma coberta mais considerável, com capacidade para 60 pessoas, onde o visitante pode contemplar a linda vista e praticar a pesca (Figura 7).

Figura 7: Esquema de trilhas da Zona de Proteção.

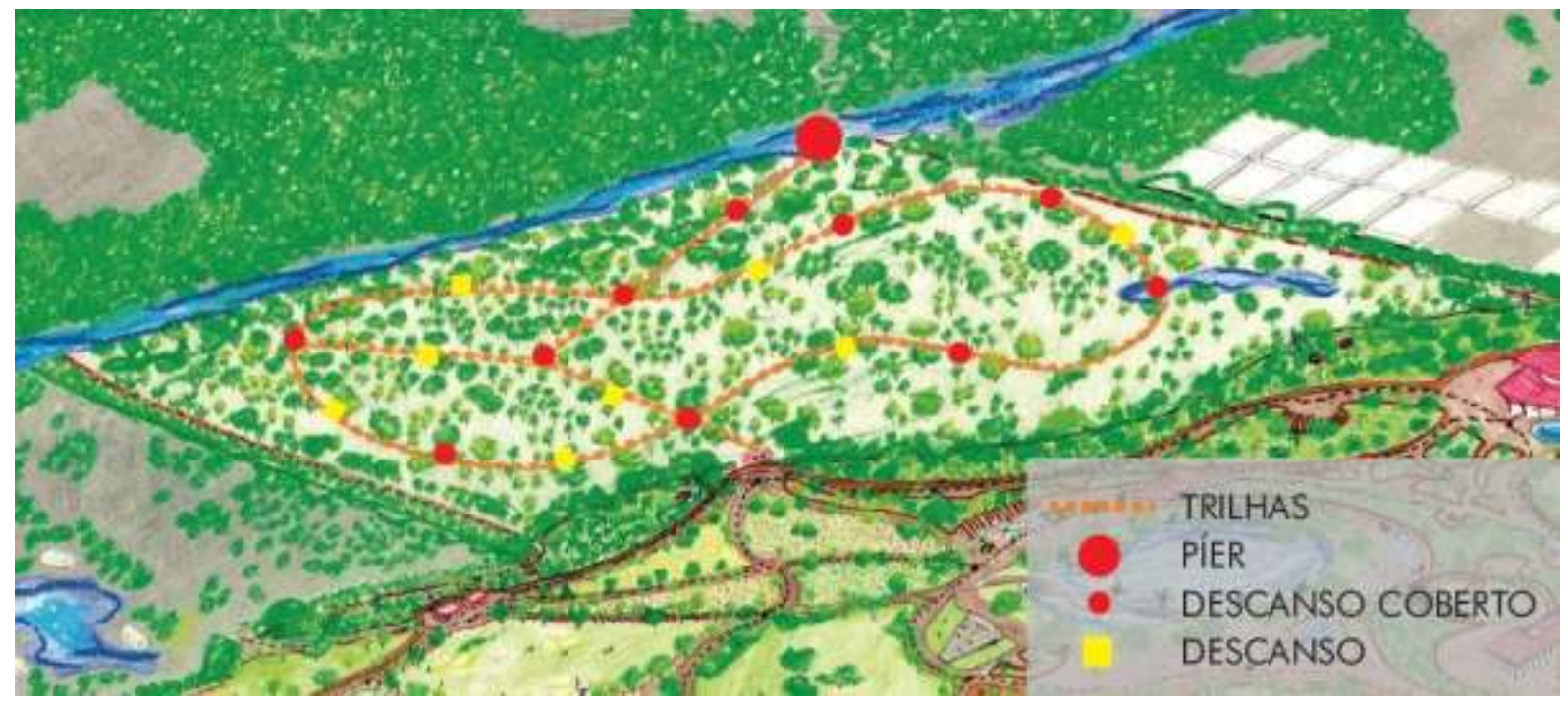

Fonte: Imagem produzida pela autora.

\section{REFERÊNCIAS BIBLIOGRÁFICAS}

ARAÚJO, Ana Maria Matos. CARLEIAL, Adelita Neto. Opulência e miséria nos bairros de fortaleza (ceará/brasil). Revista electrónica de geografía y ciencias sociales. Universidad de Barcelona. ISSN: 1138-9788. Depósito Legal: B. 21.741-98

BRAGA, Mariana Moron Saes and SCHUMACHER, Aluisio Almeida. Direito e inclusão da pessoa com deficiência: uma análise orientada pela teoria do reconhecimento social de Axel Honneth. Soc. estado. [online]. 2013, vol.28, n.2, pp. 375-392. ISSN 0102-6992. http://dx.doi.org/10.1590/S0102-69922013000200010.

BRASIL. Código Civil (2002). Código civil brasileiro e legislação correlata. - 2. ed. - Brasília: Senado Federal, Subsecretaria de Edições Técnicas, 2008. 616 p.

BRASIL. Federação Nacional das APAEs. Legislação Comentada para Pessoas Portadoras de Deficiência e Sociedade Civil Organizada/Federação Nacional das APAEs. Brasília, 2003, com 428 páginas.

BRASIL. Legislação brasileira sobre pessoas com deficiência [recurso eletrônico]. - 7. ed. Brasília : Câmara dos Deputados, Edições Câmara, 2013.

BRASIL. Ministério da Saúde. Secretaria de Atenção à Saúde. Departamento de Ações Programáticas Estratégicas. Política Nacional de Saúde da Pessoa com Deficiência / Ministério da Saúde, Secretaria de Atenção à Saúde, Departamento de Ações Programáticas Estratégicas. - Brasília : Editora do Ministério da Saúde, 2010. 24 p. : il. - (Série B. Textos Básicos de Saúde) ISBN 1. Defi ciência. 2. Políticas públicas em saúde. 3. Defesa dos defi cientes. I. Título. II. Série.

BRASIL. Senado Federal. Secretaria Especial de Comunicação Social e Secretaria de Pesquisa e Opinião. Lei 7.853, de 24 de outubro de 1989. -Dispõe sobre 0 apoio às pessoas portadoras de 


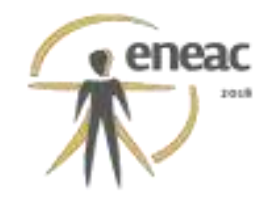

deficiência, sua integração social, sobre a Coordenadoria Nacional para Integração da Pessoa Portadora de Deficiência - Corde, institui a tutela jurisdicional de interesses coletivos ou difusos dessas pessoas, disciplina a atuação do Ministério Público, define crimes, e dá outras providências. <http://portal.mec.gov.br/seesp/arquivos/pdf/lei7853.pdf> Acesso em 14/04/2008a.

DINIZ, Debora. O que é deficiência. São Paulo: Editora Brasiliense, 2007.

DINIZ, Debora; BARBOSA, Lívia and SANTOS, Wederson Rufino dos. Deficiência, direitos humanos e justiça. Sur, Rev. int. direitos human. [online]. 2009, vol.6, n.11, pp.64-77. ISSN 18066445.

DSM-IV-TRTM - Manual diagnóstico e estatístico de transtornos mentais. trad. Cláudia Dornelles; - 4.ed. rev. - Porto Alegre: Artmed, 2002.

DUARTE, Cristiane Rose de Siqueira ; COHEN, R. Afeto e Lugar: A Construção de uma Experiência Afetiva por Pessoas com Dificuldade de Locomoção. In Anais do Seminário Acessibilidade no Cotidiano. Versão em CD. Rio de Janeiro, 2004.

FOUCAULT, M. A constituição histórica da doença mental. In: psicologia. Rio de Janeiro: Sexta. v.11, 2000 [1972]. p. 75-86. . Doença mental e

. A História da Loucura: na idade clássica. São Paulo: Perspectiva, 2005 [1961].

FRAYZE-PEREIRA, J. A. . O que é Loucura (10a.ed. ... ). 10. ed. São Paulo: Brasiliense, 1985.

GAMBOIAS, Hugo Filipe D. Arquitectura com sentidos : os sentidos como modo de viver a arquitectura. 15/10/2013. Dissertação. Universidade de Coimbra, 2013.

HALL, Edward T. A dimensão oculta. São Paulo: Martins Fontes, 2005.

OLIVER, Michael. The politics of disablement. London: MacMillan, 1990. 260p.

ORGANIZAÇÃO MUNDIAL DA SAÚDE. OMS. The World Bank. Relatório Mundial sobre a Deficiência. Trad Lexicus Serviços Linguísticos - São Paulo. SEDPcD: São Paulo, 2012, 312 p.

PALLASMAA, Juhani. Os olhos da pele: a arquitetura e os sentidos. Porto Alegre: Bookman, 2011.

SASSAKI, R. K. Atualizações semânticas na inclusão de pessoas: Deficiência mental ou intelectual? Doença ou Transtorno Mental? Revista Nacional de Reabilitação, ano IX, n. 43, $\begin{array}{lccc}\text { mar./abr. } & \text { 2005, } & \text { p.9-10. } & \text { Disponível } \\ \text { http://www.ppd.caop.mp.pr.gov.br/modules/conteudo/conteudo.php?conteudo=343 }\end{array}$

Como chamar as pessoas que têm deficiência? Revista da Sociedade Brasileira de Ostomizados, ano I, n. 1, $1^{\circ}$ sem. 2003, p.8-11. [Texto atualizado em 2009].

Vida Independente: história, movimento, liderança, conceito, filosofia e fundamentos. São Paulo: RNR, 2003.

SILVA, Maria Isabel da. Por que a terminologia "pessoas com deficiência"?. Universidade Federal Fluminense. Núcleo de Acessibilidade e Inclusão Sensibiliza - UFF, 2009. Disponível em:

$<$ http://www.proac.uff.br/sensibiliza/por-que-terminologiapessoas-com-deficiencia>. Acesso em 23.11.2009.

UNION OF THE PHYSICALLY IMPAIRED AGAINST SEGREGATION (UPIAS). Fundamental Principles of Disability. London: Union of the Physically Impaired Against Segregation, 1976. Vol. VII, núm. 146(030), 1 de agosto de 2003. 


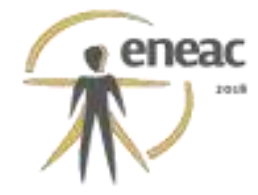

4. ANEXO (PLANO MACRO)

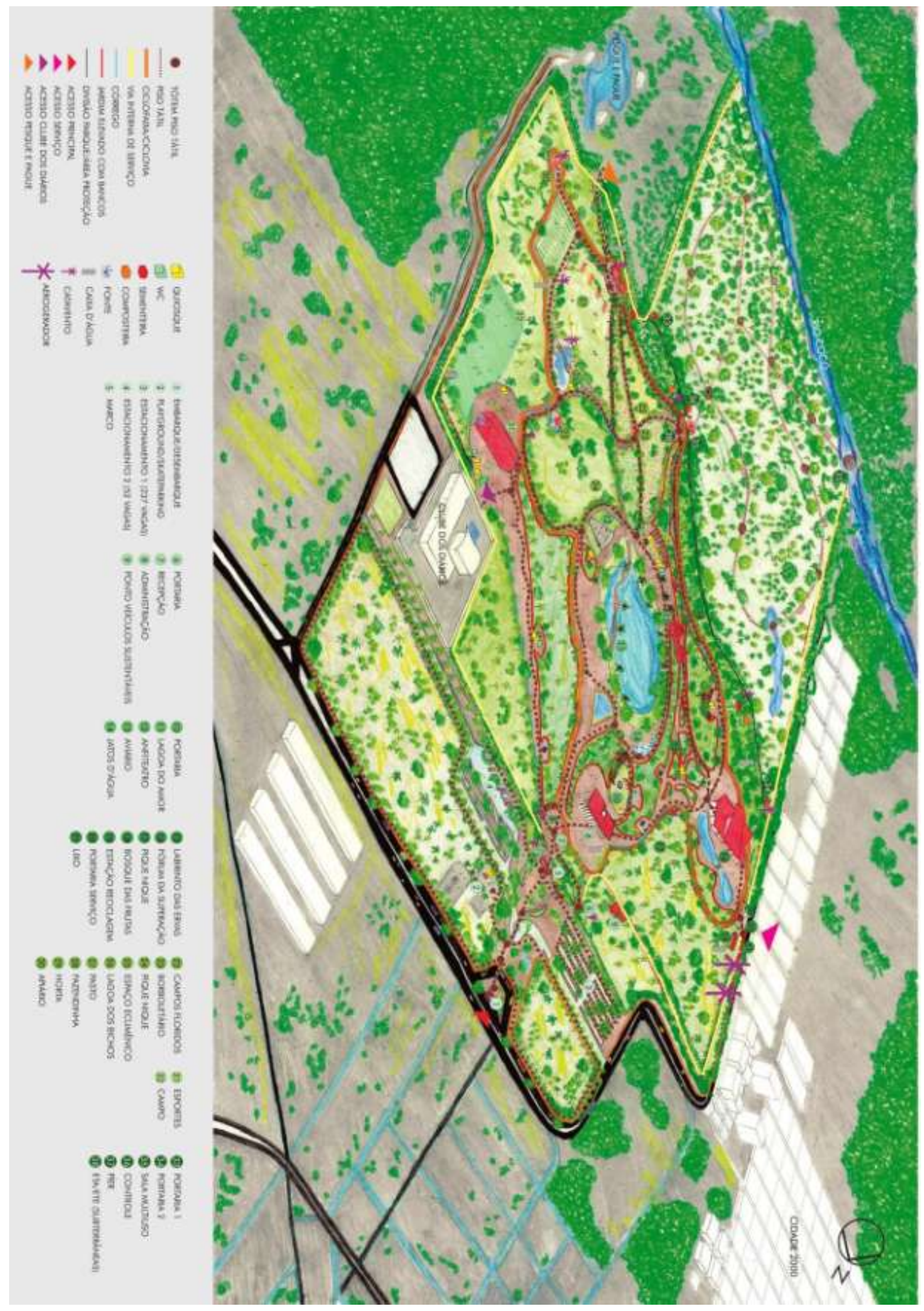

